\title{
Komparasi Algoritma Support Vector Machine Dan Naïve Bayes Dengan Algoritma Genetika Pada Analisis Sentimen Calon Gubernur Jabar 2018-2023
}

\author{
Deni Gunawan ${ }^{1}$, Dwiza Riana ${ }^{2}$, Dian Ardiansyah ${ }^{3}$, Fajar Akbar ${ }^{4}$, Salman Alfarizi5 \\ ${ }^{1,3}$ Program Studi Sistem Informasi Universitas Bina Sarana Informatika \\ 1e-mail : deni.dee@bsi.ac.id \\ ${ }^{3}$ e-mail : dian.did@bsi.ac.id \\ 5e-mail : salman.slz@bsi.ac.id \\ ${ }^{2}$ Program Studi Magister Ilmu Komputer STMIK Nusa Mandiri \\ ${ }^{2}$ dwiza@nusamandiri.ac.id \\ ${ }^{4}$ Program Studi Teknik Informatika STMIK Nusa Mandiri \\ ${ }^{4}$ fajar.fkb@nusamandiri.ac.id

\begin{tabular}{ccc}
\hline Diterima & Direvisi & Disetujui \\
$12-11-2019$ & $09-01-2020$ & $02-02-2020$ \\
\hline
\end{tabular}

\begin{abstract}
Abstrak - Kontestasi politik dalam penentuan menjadi pemimpin tingkat provinsi dalam hal ini gubernur jawa barat 2018-2023. Masyarakat yang memberikan opininya berupa tweet pada media sosial twitter menentukan bentuk dukungan atau tidaknya, sehingga perlu adanya analisis sentimen terhadap calon Gubernur agar mengetahui tingkat kepercayaan masyarakat serta terbentuk citra kepada calon Gubernur Jawa Barat 2018-2023. Akan tetapi membaca keseluruhan tweet yang tersebar dalam twitter yang berkaitan dengan masing-masing calon gubernur akan memakan waktu dan membingungkan dalam pengambilan keputusan. Klasifikasi sentimen akan mengurai masalah mengenai opini, pendapat, emosi dan prilaku dengan studi komputasi. Metode klasifikasi yang akan dibahas dalam penelitian yaitu dengan algoritma Naïve Bayes serta Support Vector Machine. Penentuan fitur menentuka hasil akurasi, dalam penentuan fitur seleksi digunakan Genetic Algorithm agar dapat meningkatan akurasi pengklasifikasian pada Support Vector Machine dan Naive Bayes. Perolehan penelitian ini yaitu klasifikasi teks dalam pola negatif atau positif dari tweet calon gubernur jawa barat 2018-2023. Pada dataset tidak seimbang Support Vector Machine menghasilkan rata-rata akurasi $92.61 \%$ dengan AUC 0,950, Naive Bayes menghasilkan rata-rata akurasi 93,29\% dengan AUC 0,525, Support Vector Machine berbasis Genetic Algorithm menghasilkan rata-rata akurasi 93,03\% dengan AUC 0,869, Naive Bayes berbasis Genetic Algorithm menghasilkan rata-rata akurasi 92,85\% dengan AUC 0,543. Hasil ini menunjukan bahwa Support Vector Machine dapat digunakan untuk membangun deteksi tweet klasifikasi positif dan negatif dengan tingkat akurasi yang tinggi. Kebaruan dari penelitian ini adalah bahwa Support Vector Machine dapat digunakan untuk mendeteksi tweet pada dataset twitter berbahasa indonesia penulis.
\end{abstract}

Kata Kunci : Sentimen Analisis, Support Vector Machine, Naive Bayes, Genetic Algorithm.

Abstract - Political dispute was determines provincial level in West Java Governor 2018- 2023. A society gave their opinions in social media on twitter to support or not, then it needed sentiment analysis against Governor prospective in order to find out trust level of community and formed the image to West Java Governor's prospective e 2018-2023. Reading the whole tweet in the twitter related to each Governor's prospective wasted time and confused on decision making. Sentiment classification decreased the problem using computer literate about opinions, behaviours and emotions of a person against the entity. This research will be discussed about the classification techniques with the Support Vector Machine method and Naive Bayes. The selection features will be affected the accuracy of classification, it was using Genetic Algorithm in order to improve the accuracy of classification on Support Vector Machine and Naive Bayes. This research resulted in texts classification of positive or negative from West Java Governor's prospective tweet s 2018-2023. On the unbalanced datasets Support Vector Machine produces an average of $92.61 \%$ accuracy with AUC 0,950, Naive Bayes generates an average of $93.29 \%$ accuracy with AUC 0,525, Support Vector Machine-based Genetic Algorithm produces an average accuracy of $93.03 \%$ with AUC 0,869, Naive Bayes-based Genetic Algorithm produces an average accuracy of $92.85 \%$ with AUC 0,543. These results suggested that Support Vector Machine can be used to build the detection positive and negative classification in tweet with a high accuracy. Support Vector Machine can be used to detect a tweet on twitter dataset speak Indonesian writer as the lastest of this research.

Keywords: Analysis Sentiment, Support Vector Machine, Naive Bayes, Genetic Algorithm 


\section{PENDAHULUAN}

Indonesia sebagai pengguna internet yang dengan pesat perkembangannya, menurut Asosiasi Penyelenggara Jasa Internet Indonesia (APJII) survei data statistik pengguna internet indonesia tahun 2016, data yang dilansir kompas 2016 tercatat pengguna internet melalui ponsel pintar berbasis android di Indonesia kini sudah mencapai 132,7 juta pengguna. Mayoritas konsumsi internet di Indonesia adalah untuk menggunakan jejaring media social, dengan pengguna media sosial pada di angka $40 \%$, adapaun pengguna aktifnya sebesar $34 \%$. Dalam mengakses media sosial tersebut berada di angka 39\% dengan perangkat mobile.

Kampanye politik akan sering kali terjadi dalam proses perebutan panggung politik sehingga menjadi sesuatu hal yang lumrah dalam suatu negara. Tidak dapat dielakan bahwa kampanye yang dilakaukan para actor politik merupakan pencarian segmentasi pemilih agar mendapat dukungan penuh (Alfiah, Susanti, Kristinna, Ardiansyah, \& Pradipta, 2015).

Beberapa tahun terakhir telah melihat gelombang kepentingan dalam metode komputasi yang memiliki pengaruh terhadap opinion mining, untuk deteksi subyektivitas, dan analisis sentiment (Balahur, Mihalcea, \& Montoyo, 2014). Twitter adalah layanan microblogging real time populer yang memungkinkan pengguna untuk berbagi informasi singkat dikenal sebagai tweets yang dibatasi 140 karakter. Twitter adalah platform yang ideal untuk ekstraksi pendapat masyarakat umum pada isu-isu spesifik, mengungkapkan sesuatu keluhan dan meluapkan sentimen yang negatif atau positif. (Sarlan, Nadam, \& Basri, 2015)(Wahyudi \& Putri, 2016). Bahkan terdapat perusahaan mendalami reaksi pengguna dalam sebuah produk manufactur dengan platform twitter (Wahyudi \& Putri, 2016). Twitter kini lebih banyak karakter yang disediakan dalam setiap cuitan, yang sebelumnya 140 menjadi 280 karakter (Bohang, 2017).

Jutaan bahkan ratusan juta pengguna dapat mencurahkan pemikiran serta opini mereka mengenai aspek-aspek kehidupan pada platform microblogging pribadinya. Oleh karenanya cuitan pada twitter adalah basis informasi yang dapat mempertimbangkan sebuah keputusan serta menganalisis sentimen. Kemunculan media sosial memberikan keleluasaan dalam mengungkapkan pemikiran dan mengekspresikan setiap penguna dalam topik yang bermacam-macam pada wadah yang sama (Balahur et al., 2014). Dengan pengguna telah hampir 600 juta serta pesan per hari mencapai 250 juta, menjadikan twitter sumber informasi serta peluang besar bagi organisasi dalam mengontrol merek mereka dari pesaing dan postingan cuitan di pasar public (Balahur et al., 2014).

Beberapa penelitian sebelumnya mengenai ulasan film menggunakan klasifikasi Support Vector
Machine (SVM) dan Particle Swarm Optimization (PSO) atau sentimen opini analisis (Basari, Hussin, Ananta, \& Zeniarja, 2013). Machine Learning yang memperkenalkan klasifikasi teks seperti Naive Bayes, K-NN, SVM dan Rocchio Classification (Ramesh \& Sathiaseelan, 2015).

Pada penelitian ini akan menjelaskan lebih detail untuk mengoptimasi Algoritma klasifikasi. Menurut Zukhri Optimasi adalah proses menyelesaikan masalah tertentu yang berada pada kondisi yang paling menguntungkan dari sudut pandang. Yang memecahkan masalah terkait erat dengan data yang dapat diekspresikan edinone atau beberapa variabel (Zukhri, 2014). Algoritma Genetika adalah metode heuristik yang dikembangkan berdasarkan prinsipprinsip genetika dan proses seleksi alam teori evolusi Darwin. Metode optimasi dikembangkan oleh John Holl dan sekitar tahun 1960 dan dipopulerkan oleh salah seorang muridnya, David Gold bergin tahun 1980-an. Penyempurnaan proses pencarian dalam algoritma terjadi seperti pemilihan individu untuk bertahan dalam proses evolusi (Zukhri, 2014).

Dari uraian tersebut diatas, maka dalam penelitian ini akan digunakan metode Support Vector Machine dan Naïve bayes yang dipadu dengan Algoritma Genetika yang akan mengoptimasi parameter Support Vector Machine.

\section{METODOLOGI PENELITIAN}

\section{A. Perencanaan Penelitian}

Pada dasarnya, penelitian merupakan suatu investigasi yang terorganisasi, yang dilakukan untuk menyajikan suatu informasi dan memecahkan masalah. Metode penelitian yang digunakan penulis menggunakan metode penelitian eksperimen. Adapun metode penelitian yang penulis gunakan melalui beberapa tahapan sebagai berikut:

a. Pengumpulan Data

Data yang digunakan untuk melakukan eksperimen dikumpulkan melalui tweet dari twitter diambil menggunakan aplikasi rapidminer.

b. Pengolahan Data awal

Menentukan metode yang akan dipakai pada proses pengujian data. Berdasarkan metode terdahulu dengan ketentuan metode yang terbaik dari pengklasifikasian teks. Penelitian ini menggunakan metode Algoritma Support Vector Machine dan Naïve Bayes.

c. Metode yang Diusulkan

Metode yang diajukan dalam hal ini penulis melakukan komparasi atau perbandingan metode SVM dan NB dengan melakukan peningkatan optimasi yang digunakan, yaitu dengan Genetic Algorithm (GA).

d. Eksperimen dan Pengujian Metode 
Eksperimen yang dilakukan peneliti, menggunakan framework RapidMiner 8.2. untuk mengolah data tweet sebagai alat bantu pengukuran sehingga menghasilkan nilai akurasi yang akurat.

e. Evaluasi Performa dan Validasi Hasil Evaluasi

Evaluasi menggunakan confusion matrix untuk mengetahui akurasi, presisi dan recall. Menurut Han confusion matrix adalah alat yang sangat berguna untuk menganalisis seberapa baik classifier dapat mengidentifikasi tupel dari kelas yang berbed (Han, Kamber, \& Pei, 2012). Dalam beberapa confusion matrix dikenal istilah True positive yang merujuk pada tuple positif yang diberi label dengan benar oleh classifier, sedangkan True negative adalah tuple negatif yang diberi label dengan benar oleh classifier. Ada juga false positive yang merupakan tuple negatif yang salah diberi label oleh classifier, dan false negative adalah tuple positif yang tidak diberi label dengan benar oleh classifier. Kurva ROC (Receiver Operating Characteristic) membagi hasil positif pada sumbu $\mathrm{y}$ dan hasil negatif pada sumbu $\mathrm{x}$ dalam bentuk AUC (Area Under the Curve). Jadi semakin besar area di bawah kurva, semakin baik hasil prediksi. yang bisa mengubah orientasi pendapat juga tidak sebanding dengan yang buruk (Witten, Frank, Hall, \& Pal, 2016).

\section{B. Pengumpulan Data Awal}

Peneliti menggunakan data tweet pemilihan gubernur jawa barat 2018. Data yang dikumpulkan dari www.twitter.com dibantu dengan framework rapid miner, untuk jenis data tweet pasangan calon gubernur jawa barat periode 2018-2023 yang terdapat 4 pasang calon gubernur jawa barat diambil data sebanyak 9637 data, untuk data pasangan calon gubernur Ridwan Kamil-Uu Ruhzanul Ulum sebanyak 3647 data, Tubagus Hasanuddin-Anton Charliyan 2037 data, Sudrajat-Ahmad Syaikhu 2358 data dan Deddy Mizwar-Dedi Mulyadi 1595 data. Kemudian dikelompokkan ke dalam tweet positif dan tweet negatif. Data tweet yang penulis mengunduh merupakan data tweet pertanggal 20 Mei, 04 Juni, 22 Juni dan 27 Juni 2018.

\section{Pengolahan Data Awal}

Untuk mehindari pengolahan data yang tidak diperlukan maka dilakukan remove duplicate, sehingga penulis hanya menggunakan 2010 tweet positif dan 633 tweet negatif sebagai data training. Kemudian dataset tersebut diolah melalui tahapan preprocessing 4 (empat) proses, diantaranya:

a. Tokenization

Proses memotong setiap kata dalam teks dan mengubah huruf dalam dokumen menjadi huruf kecil. Hanya huruf yang diterima, sedangkan karakter khusus atau tanda baca akan dihilangkan. Jadi hasil dari proses Tokenization adalah kata-kata yang merupakan penyusun kalimat atau string yang dimasukan tanpa ada tanda baca (Crc, Hofmann, \& Chisholm, 2016).

b. Indonesian Stemming

Proses stemming adalah variasi dari kata di kelompokkan dengan penghilangan imbuhan sehingga memiliki kata dasar yang sama (Aggarwal, 2015).. Proses pencarian kata dalam sebuah dokumen agar mengetahui seberapa banyak kata yang kemudian dilakukan pembobotan menggunakan TFIDF.

c. Indonesian Stopword Removal

Proses Stopword Removal setiap kata yang selalu muncul namun sedikit memberikan informasi dari isi dokumen, sebagai contoh seperti “apa","sebuah","untuk", kata sambung dan sebagainya (Aggarwal, 2015)(Crc et al., 2016).

d. Generate N-Gram

Generate N-Gram merupakan urutan kombinasi kata yang berdekatan dari $\mathrm{n}$ item dari ekstrak teks dalam sebuah dokumen dari dua, tiga, empat atau lebih kata. N-gram yang umum digunakan dalam text mining adalah unigrams, bigrams, dan trigram. Bigram digunakan untuk mengenerator fitur positif dan negatif (Crc et al., 2016).

\section{Metode Yang Usulkan}

Dalam penelitian ini metode algoritma yang diusulkan adalah penggunaan 2 (dua) jenis metode algoritma yaitu Support Vector Machine (SVM) dan Nä̈ve Bayes (NB) yang kemudian di tambah sebuah seleksi fitur yaitu Genetic Algorithm (GA) agar akurasi pengklasifikasi dapat meningkat. Penulis membandingkan ke dua metode algoritma tersebut untuk diketahui metode algoritma terbaik untuk diterapkan bersama dengan seleksi fitur Genetic Algorithm (GA). Penulis menggunakan Support Vector Machine (SVM) dalam pengklasifikasi karena merupakan teknik machine learning yang populer untuk klasifikasi teks serta memiliki performa yang baik pada banyak domain. Kemampuan SVM dalam mengidentifikasi hyperplane secara terpisah diantara dua kelas berbeda sehingga termaksimalkan (Indrayuni, 2016). SVM menjamin untuk memaksimalkan jarak antara data yang paling dekat dengan hyperplane. Pengkalsifikasi Naïve Bayes (NB) merupakan metode klasifikasi teks berdasarkan probilitas kata kunci dalam membandingkan dokumen latih dan dokumen uji. Keudanya dibandingkan melalui beberapa tahanp persamaan, yang akhirnya diperoleh hasil probalitas tertinggi yang di tetapkan sebagai kategori dokumen baru. Lihat gambar 1 . untuk model yang diusulkan secara lebih detail. 


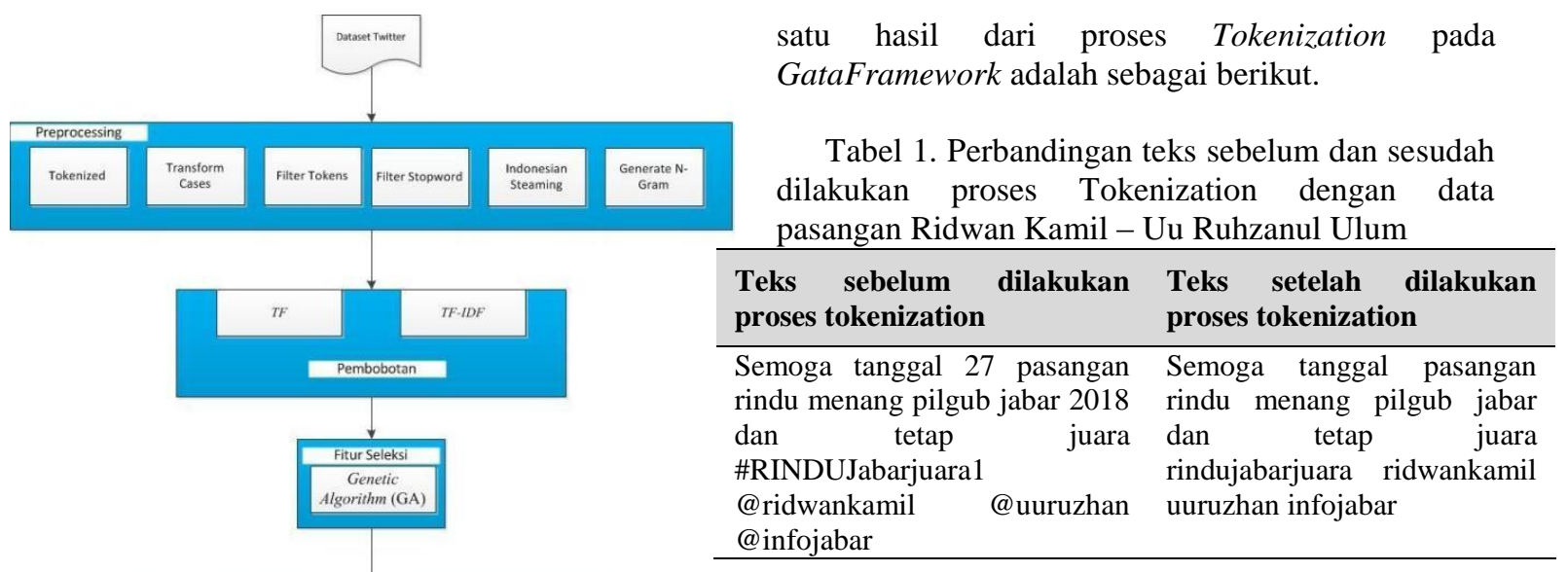

\section{B. Indonesian Stopword Removal}

Proses Stopword Removal setiap kata yang selalu muncul namun sedikit memberikan informasi dari isi dokumen, sebagai contoh seperti "apa","sebuah","untuk", kata sambung dan sebagainya.

Tabel 2. Perbandingan teks sebelum dan sesudah dilakukan proses Indonesian Stopword Removal dengan data pasangan Ridwan Kamil - Uu Ruhzanul Ulum

\begin{tabular}{|c|c|}
\hline 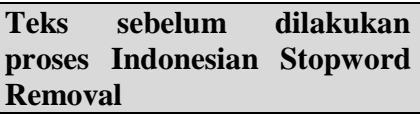 & $\begin{array}{l}\text { Teks setelah dilakukan } \\
\text { proses Indonesian Stopword } \\
\text { Removal }\end{array}$ \\
\hline $\begin{array}{l}\text { Semoga tanggal pasangan rindu } \\
\text { menang pilgub jabar dan tetap } \\
\text { juara rindujabarjuara } \\
\text { ridwankamil uuruzhan infojabar }\end{array}$ & $\begin{array}{l}\text { Semoga tanggal pasangan } \\
\text { rindu menang pilgub jabar } \\
\text { juara } \\
\text { ridwankamil rindujabarjuara } \\
\text { infojabar }\end{array}$ \\
\hline
\end{tabular}

\section{Indonesian Stemming}

Proses stemming adalah variasi dari kata di kelompokkan dengan penghilangan imbuhan sehingga memiliki kata dasar yang sama. Proses pencarian kata dalam sebuah dokumen agar mengetahui seberapa banyak kata yang kemudian dilakukan pembobotan menggunakan TF-IDF.

Tabel 3. Perbandingan teks sebelum dan sesudah dilakukan proses Indonesian Stemming dengan data pasangan Ridwan Kamil - Uu Ruhzanul Ulum (GA) dan Naive Bayes berbasis Genetic Algorithm (GA). Penerapan evaluasi algoritma tersebut menggunakan confusion matrix untuk menghitung Akurasi, Presisi dan Recall. Dengan semakin besar area dibawah kurva (AUC), semakin baik hasil prediksi.

\section{HASIL DAN PEMBAHASAN}

\begin{tabular}{ll}
\hline $\begin{array}{l}\text { Teks sebelum dilakukan } \\
\text { proses Indonesian Stemming }\end{array}$ & $\begin{array}{l}\text { Teks setelah } \\
\text { proses } \\
\text { Stemming }\end{array}$ \\
\hline $\begin{array}{l}\text { Semoga tanggal pasangan rindu } \\
\text { Indonesian }\end{array}$ \\
menang pilgub jabar juara \\
rindujabarjuara ridwankamil \\
uuruzhan infojabar
\end{tabular}

\section{A. Tokenization}

Proses Tokenization berfungsi untuk menghilangkan tanda baca, symbol dan katakter yang bukan berupa huruf pada setiap tweet. Salah

\section{Generate N-Gram}

Generate N-Gram merupakan urutan kombinasi kata yang berdekatan dari $\mathrm{n}$ item dari ekstrak teks 
dalam sebuah dokumen dari dua, tiga, empat atau lebih kata. N-gram yang umum digunakan dalam text mining adalah unigrams, bigrams, dan trigram. Bigram digunakan untuk mengenerator fitur positif dan negatif.

Tabel 4. Perbandingan teks sebelum dan sesudah dilakukan proses $\mathrm{N}$-Gram dengan data pasangan Ridwan Kamil - Uu Ruhzanul Ulum

\begin{tabular}{|c|c|}
\hline $\begin{array}{l}\text { Teks sebelum dilakukan } \\
\text { proses } \text { N-Gram }\end{array}$ & $\begin{array}{l}\text { Teks setelah dilakukan } \\
\text { proses } \\
\text { N-Gram }\end{array}$ \\
\hline $\begin{array}{l}\text { Semoga tanggal pasang rindu } \\
\text { menang pilgub jabar juara } \\
\text { rindujabarjuara ridwankamil } \\
\text { uuruzhan infojabar }\end{array}$ & $\begin{array}{l}\text { semoga semoga_tanggal } \\
\text { tanggal tanggal_pasang } \\
\text { pasang pasang_rindu rindu } \\
\text { rindu_menang menang } \\
\text { menang_pilgub pilgub } \\
\text { pilgub_jabar jabar jabar_juara } \\
\text { juara juara_rindujabarjuara } \\
\text { rindujabarjuara } \\
\text { rindujabarjuara_ridwankamil } \\
\text { ridwankamil } \\
\text { ridwankamil_uuruzhan } \\
\text { uuruzhan uuruzhan_infojabar } \\
\text { infojabar }\end{array}$ \\
\hline
\end{tabular}

\section{E. Proses Klasifikasi}

Klasifikasi didefinisikan sebagai proses menetapkan kategori atau beberapa kategori di antara yang sudah ditentukan sebelumnya untuk setiap item data (Jo, 2018). Dengan menentukan dari sebuah kalimat untuk menjadi sebuah kelas positif dan kelas negatif berdasarkan nilai probabilitas dari yang lebih besar. Termasuk kedalam class positif ketika nilai probabilitas kalimat lebih besar pada class positif. Jika dalam kategori class negatif ketika nilai probabilitas kalimat lebih besar pada class negatif. Model pengklasifikasian yang di implementasikan pada Rapidminer 8.2 bisa di lihat pada gambar 2 dan 3.

Tahap pengklasifikasian teks menggunakan data training dari masing- masing data pasangan calon Gubernur Jawa Barat yang terdiri dari Ridwan Kamil- Uu Ruhzanul Ulum 987 data tweet, Tubagus Hasanuddin-Anton Charliyan 643 data tweet, Sudrajat-Ahmad Syaikhu 541 data tweet dan Deddy Mizwar-Dedi Mulyadi 470 data tweet . Masingmasing data pasangan calon terdapat tweet yang dianggap tweet positif dan tweet negatif.

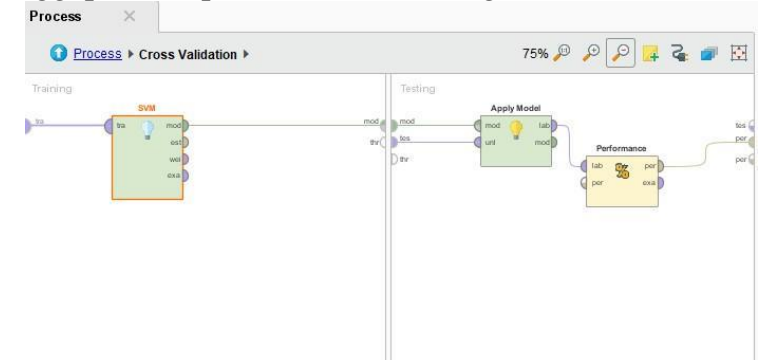

Gambar 2. Model Klasifikasi SVM

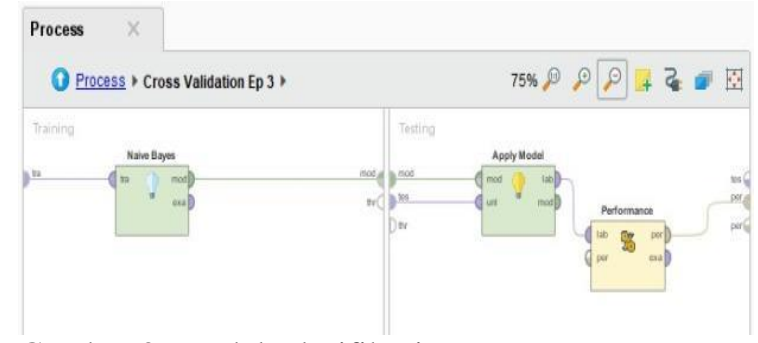

Gambar 3. Model Klasifikasi NB

\section{F. Pembobotan dan pemilihan fitur seleksi}

Metode pembobotan Fitur yang akan digunakan adalah Term Frequency Invers Document Frequency (TF-IDF) dan pemilihan seleksi fitur yang akan diujicoba pertama kali yaitu model algoritma Support Vector Machine (SVM) dan Nä̈ve Bayes dengan pengujian 10 Fold Cross Validation. Selanjutnya pemilihan seleksi fitur yang akan di ujicoba berikutnya yaitu Genetic Algorithm (GA) dengan model algoritma Support Vector Machine (SVM) dan Genetic Algorithm (GA) dengan model Naïve Bayes (NB) pengujian 10 Fold Cross Validation. Model pembobotan yang di implementasikan pada Rapidminer 8.2 bisa di lihat pada gambar 3 .

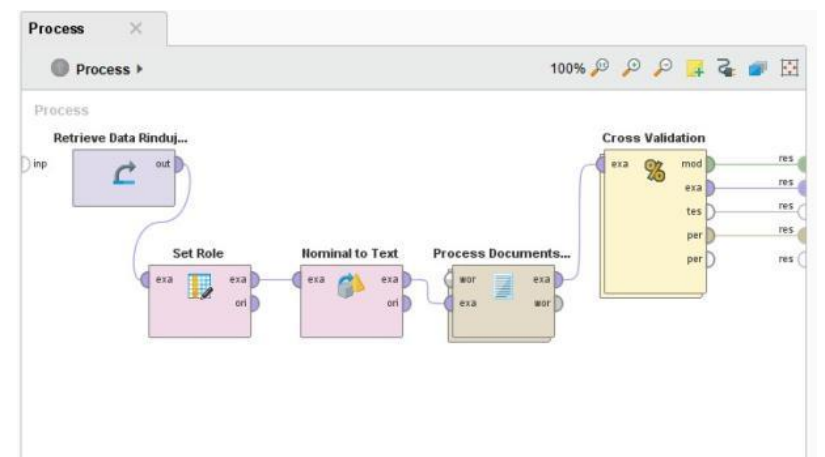

Gambar 4. Model Pembobotan TF-IDF dan KFold Cross Validation

G. Hasil Eksperimen Pengujian Metode.

a. Metode Support Vector Machine (SVM).

1) Model Klasifikasi Support Vector Machines (SVM)

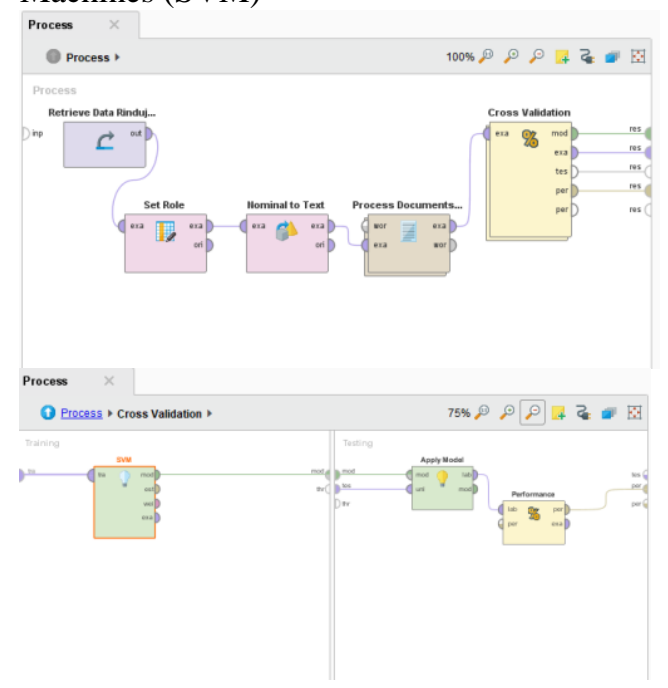


Gambar 5. Model Klasifikasi SVM

2) Hasil Eksperimen

Nilai accuracy, precision dan recall dari data training pasangan calon Ridwan Kamil-Uu Ruhzanul Ulum dapat dihitung dengan menggunakan RapidMiner. Hasil terbaik pada eksperimen SVM di atas adalah dengan $\mathrm{C}=0.0$ dan Epsilon $=0.9$ serta population size $=5$ dihasilkan Accuracy 89.08\% dan AUC $=0.947$.

3) Confusion Matrix

Hasil uji terbaik pada pengklasifikasian data tweet Ridwan Kamil-Uu Ruhzanul Ulum menggunakan Algoritma Support Vector Machine (SVM) dapat di lihat pada gambar berikut:

Tabel 5. Model Confusion Matrix Untuk Metode SVM Rindu

\begin{tabular}{lccc}
\hline \multicolumn{1}{l}{$\begin{array}{l}\text { Accuracy : 89.08 \%,+/- 2.95 \% } \\
\text { (Mikro avarage: 89.08 \%) }\end{array}$} & \multicolumn{1}{c}{$\begin{array}{l}\text { True } \\
\text { Positif }\end{array}$} & $\begin{array}{l}\text { True } \\
\text { Negatif }\end{array}$ & $\begin{array}{l}\text { Class } \\
\text { Precission }\end{array}$ \\
\hline $\begin{array}{l}\text { Prediksi } \\
\text { Positif }\end{array}$ & 754 & 100 & $88,29 \%$ \\
\hline $\begin{array}{l}\text { Prediksi } \\
\text { Negatif }\end{array}$ & 8 & 127 & $94,07 \%$ \\
\hline $\begin{array}{l}\text { Class } \\
\text { Recall }\end{array}$ & $98.95 \%$ & $55.95 \%$ & \\
\hline
\end{tabular}

Hasil perhitungan yang divisualisasikan dengan kurva ROC dapat di lihat pada gambar 6 yang mengekspresikan confusion matrix dari tabel 5. Garis horizontal adalah false positive dan garis vertikal true positive.

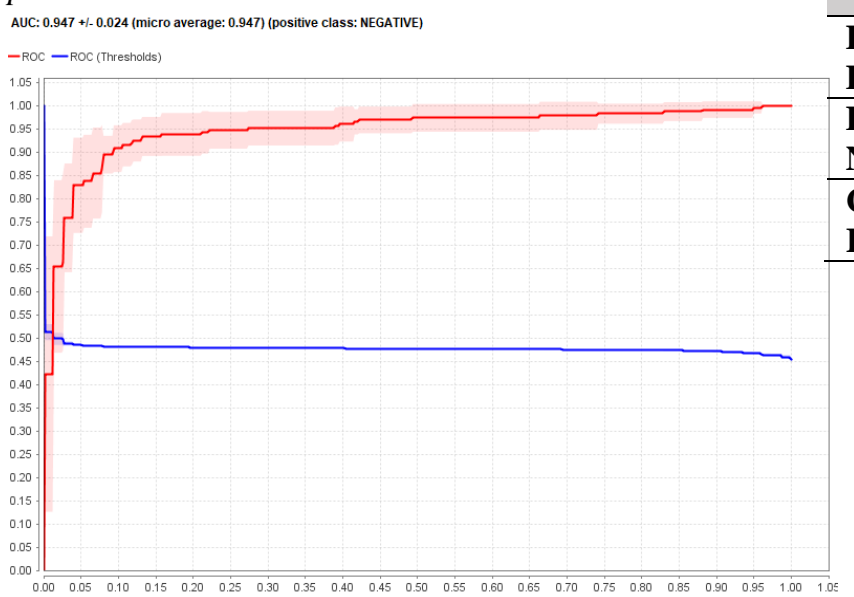

Gambar 6. Kurva ROC SVM

b. Metode Naïve Bayes (NB)

1) Model Klasifikasi NB

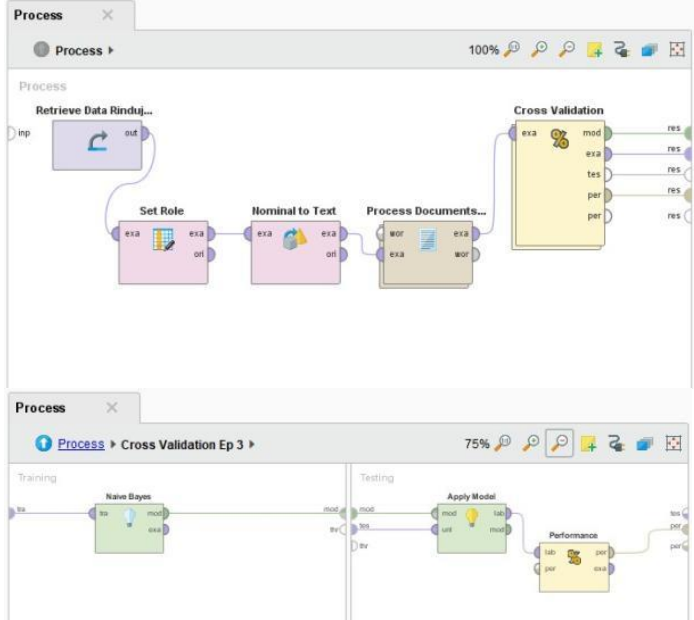

Gambar 7. Model Klasifikasi NB

2) Hasil Eksperimen

Nilai accuracy, precision dan recall dari data training pasangan calon Ridwan KamilUu Ruhzanul Ulum dapat dihitung dengan menggunakan RapidMiner. Hasil terbaik pada eksperimen NB di atas dihasilkan Accuracy $90.19 \%$ dan $\mathrm{AUC}=0.531$.

3) Confusion Matrix

Hasil uji terbaik pada pengklasifikasian data tweet Ridwan Kamil-Uu Ruhzanul Ulum menggunakan Algoritma Nä̈ve Bayes (NB) dapat di lihat pada gambar berikut :

Tabel 6. Model Confusion Matrix Untuk Metode NB Rindu

Accuracy : $90.19 \%,+/-2.74 \%$

(Mikro avarage: $90.19 \%$ )

\begin{tabular}{llll} 
& $\begin{array}{l}\text { True } \\
\text { Positif }\end{array}$ & $\begin{array}{l}\text { True } \\
\text { Negatif }\end{array}$ & $\begin{array}{l}\text { Class } \\
\text { Precission }\end{array}$ \\
\hline $\begin{array}{l}\text { Prediksi } \\
\text { Positif }\end{array}$ & 715 & 50 & $93,46 \%$ \\
\hline $\begin{array}{l}\text { Prediksi } \\
\text { Negatif }\end{array}$ & 47 & 177 & $79,02 \%$ \\
\hline $\begin{array}{l}\text { Class } \\
\text { Recall }\end{array}$ & $93.83 \%$ & $77.97 \%$ & \\
\hline
\end{tabular}

Hasil perhitungan yang divisualisasikan dengan kurva ROC dapat di lihat pada gambar 8 yang mengekspresikan confusion matrix dari tabel 6 . Garis horizontal adalah false positive dan garis vertikal true positive.

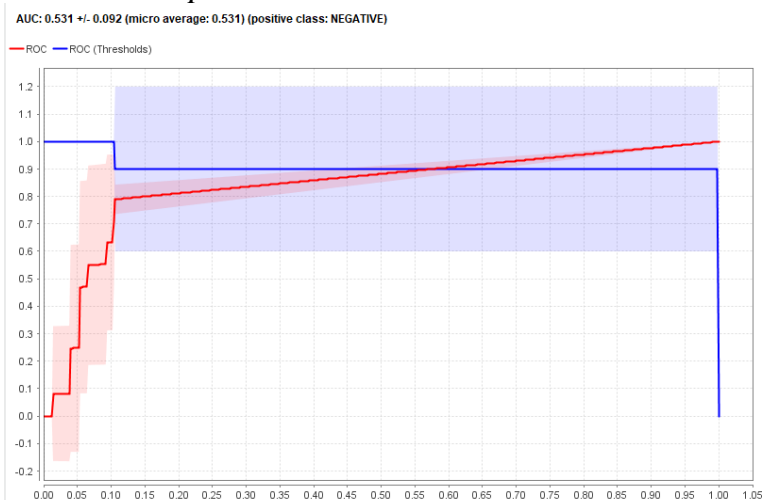


Gambar 8. Kurva ROC NB

c. Model SVM-GA

1) Model Klasifikasi SVM-GA
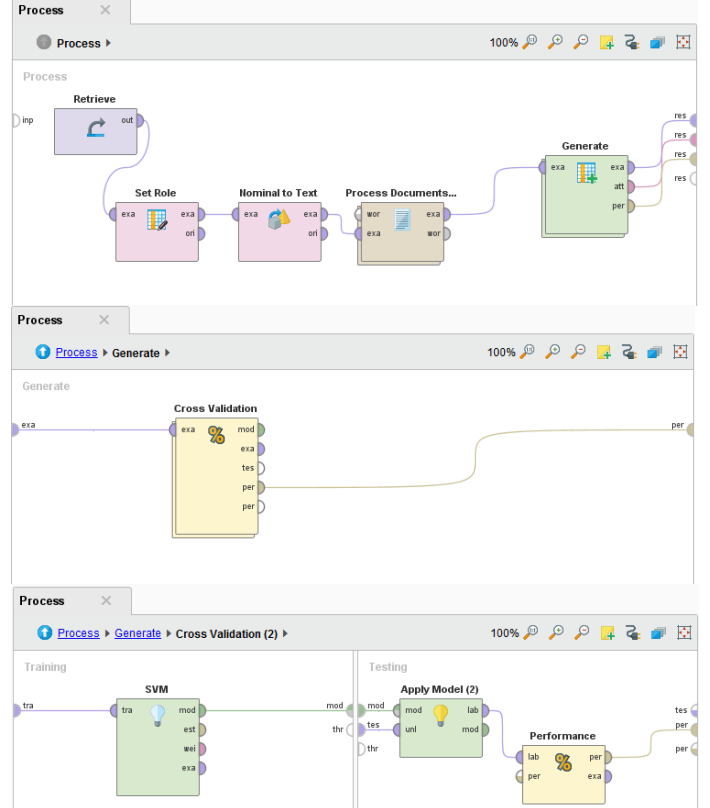

Gambar 3. Model Klasifikasi SVM-GA

2) Hasil Eksperimen

Nilai accuracy, precision dan recall dari data training pasangan calon Ridwan Kamil-Uu Ruhzanul Ulum dapat dihitung dengan menggunakan RapidMiner. Hasil terbaik pada eksperimen SVM di atas adalah dengan $\mathrm{C}=0.0$ dan Epsilon $=0.0$ serta population size $=5$ dihasilkan Accuracy $88.98 \%$ dan AUC $=0.955$.

3) Confusion Matrix

Hasil uji terbaik pada pengklasifikasian data tweet Ridwan Kamil-Uu Ruhzanul Ulum menggunakan Algoritma Support Vector Machine berbasis Genetic Algorithm (SVM-GA) dapat di lihat pada gambar berikut:

Tabel 7. Model Confusion Matrix Untuk Metode SVM - GA Rindu

\begin{tabular}{lccc}
\hline \multicolumn{4}{l}{$\begin{array}{l}\text { Accuracy : 88.98 \%, +/- 2.13 \% } \\
\text { (Mikro avarage: 88.98 \%) }\end{array}$} \\
\hline & $\begin{array}{l}\text { True } \\
\text { Positif }\end{array}$ & $\begin{array}{l}\text { True } \\
\text { Negatif }\end{array}$ & Class Precission \\
\hline $\begin{array}{l}\text { Prediksi } \\
\text { Positif }\end{array}$ & 759 & 106 & $87,75 \%$ \\
\hline $\begin{array}{l}\text { Prediksi } \\
\text { Negatif }\end{array}$ & 3 & 121 & $97,57 \%$ \\
\hline $\begin{array}{l}\text { Class } \\
\text { Recall }\end{array}$ & $99.61 \%$ & $53.30 \%$ & \\
\hline
\end{tabular}

Hasil perhitungan yang divisualisasikan dengan kurva ROC dapat di lihat pada gambar 10 yang mengekspresikan confusion matrix dari tabel 7. Garis horizontal adalah false positive dan garis vertikal true positive.

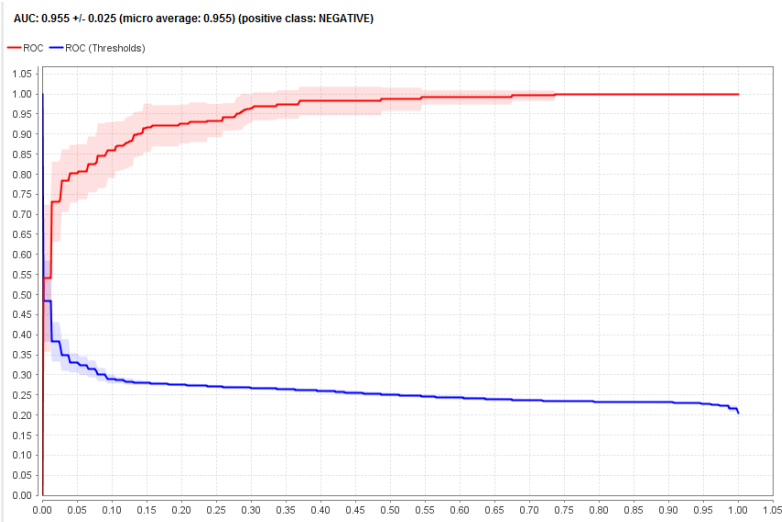

Gambar 10. Kurva ROC SVM-GA

d. Model NB-GA

1) Model Klasifikasi NB-GA

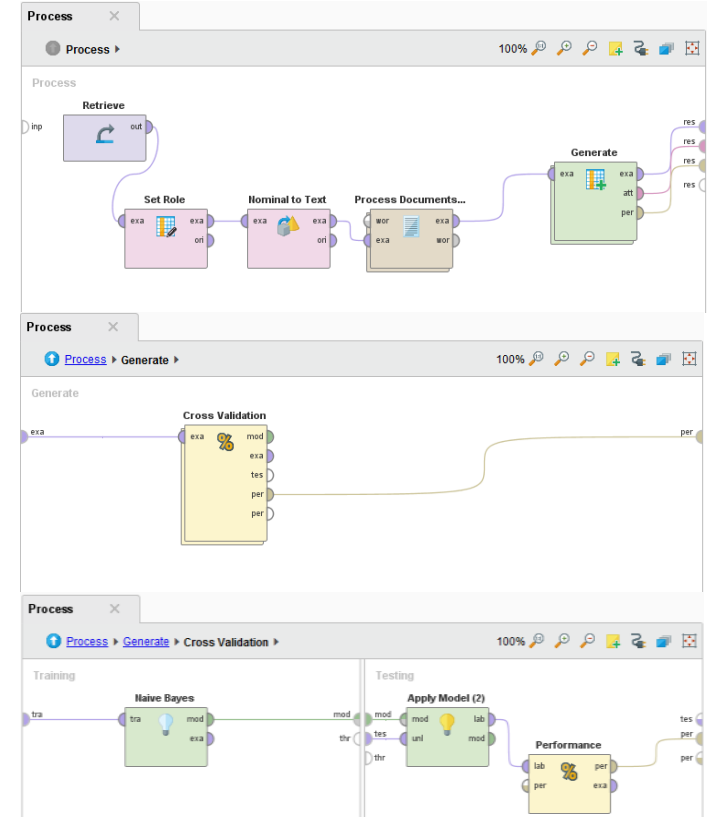

Gambar 11. Model Klasifikasi NB-GA

2) Hasil Eksperimen

Nilai accuracy, precision dan recall dari data training pasangan calon Ridwan Kamil-Uu Ruhzanul Ulum dapat dihitung dengan menggunakan RapidMiner. Hasil terbaik pada eksperimen NB-GA di atas adalah dengan $\mathrm{C}=$ 0.0 dan Epsilon $=0.0$ serta population size $=5$ dihasilkan Accuracy $89.99 \%$ dan AUC $=0.528$.

3) Confusion Matrix

Hasil uji terbaik pada pengklasifikasian data tweet Ridwan Kamil-Uu Ruhzanul Ulum menggunakan Algoritma Naive Bayes berbasis Genetic Algorithm (NB-GA) dapat di lihat pada gambar berikut :

Tabel 8. Model Confusion Matrix Untuk Metode

NB - GA Rindu 


\begin{tabular}{|c|c|c|c|}
\hline \multicolumn{4}{|c|}{$\begin{array}{l}\text { Accuracy : } 89.99 \%,+/-3.87 \% \\
\text { (Mikro avarage: } 89.99 \% \text { ) }\end{array}$} \\
\hline & $\begin{array}{l}\text { True } \\
\text { Positif }\end{array}$ & $\begin{array}{l}\text { True } \\
\text { Negatif }\end{array}$ & $\begin{array}{l}\text { Class } \\
\text { Precission }\end{array}$ \\
\hline $\begin{array}{l}\text { Prediksi } \\
\text { Positif }\end{array}$ & 694 & 31 & $95,72 \%$ \\
\hline $\begin{array}{l}\text { Prediksi } \\
\text { Negatif }\end{array}$ & 68 & 196 & $74,24 \%$ \\
\hline $\begin{array}{l}\text { Class } \\
\text { Recall }\end{array}$ & $91.08 \%$ & $86.34 \%$ & \\
\hline
\end{tabular}

Hasil perhitungan yang divisualisasikan dengan kurva ROC dapat di lihat pada gambar 12 yang mengekspresikan confusion matrix dari tabel 8 . Garis horizontal adalah false positive dan garis vertikal true positive.

\begin{tabular}{l|l|l|l|l}
\hline \multirow{2}{*}{$\begin{array}{l}\text { Calon } \\
\text { Gubernur }\end{array}$} & \multicolumn{2}{|l|}{ Naïve Bayes } & NB + GA \\
\cline { 2 - 5 } Rindu & Accuracy & AUC & Accuracy & AUC \\
\hline Hasanah & $90.19 \%$ & 0.531 & $89.99 \%$ & 0.528 \\
\hline Asyik & $96.10 \%$ & 0.500 & $95.33 \%$ & 0.550 \\
\hline DuaDM & $95.57 \%$ & 0.532 & $93.53 \%$ & 0.594 \\
\hline
\end{tabular}

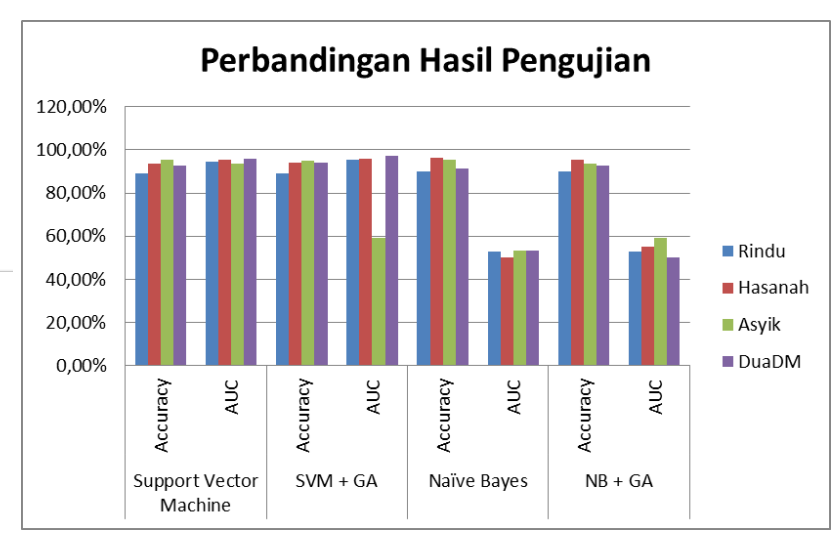

Gambar 13. Diagram Perbandingan Hasil Pengujian Terbaik

\section{KESIMPULAN}

Dalam penelitian ini penulis melakukan

\section{Gambar 12. Kurva ROC NB-GA}

\section{H. Analisis Evaluasi Hasil dan Validasi Model}

Dari hasil pengujian di atas, pengukuran akurasi menggunakan confusion matrix dan kurva ROC terbukti bahwa hasil pengujian algoritma NB memiliki nilai akurasi yang lebih tinggi dibandingkan dengan algoritma SVM, SVM berbasis GA dan NB berbasis GA. Setelah dilakukan pengujian data calon Gubernur periode 2018-2023 dengan calon Gubernur Rindu pada hasil pengujian tertinggi yaitu dengan model algoritma NB sebesar $90.19 \%$, untuk calon Gubernur Hasanah hasil pengujian tertinggi terdapat pada model algoritma NB sebesar $96.10 \%$, pada calon Gubernur Asyik sebesar $95.57 \%$ pada model algoritma NB sedangkan calon Gubernur DuaDM akurasi tertinggi pada model algoritma SVM berbasis GA.

Perbandingan hasil pengujian terbaik dapat di lihat pada tabel 9 dan gambar 13 di bawah ini

Tabel 9. Perbandingan hasil pengujian terbaik

\begin{tabular}{l|l|l|l|l}
\hline \multirow{2}{*}{$\begin{array}{l}\text { Calon } \\
\text { Gubernur }\end{array}$} & \multicolumn{2}{|l|}{$\begin{array}{l}\text { Support } \\
\text { Machine }\end{array}$} & Vector & \multicolumn{2}{l}{ SVM + GA } \\
\cline { 2 - 5 } Accuracy & AUC & Accuracy & AUC \\
\hline Rindu & $89.08 \%$ & 0.947 & $88.98 \%$ & 0.955 \\
\hline Hasanah & $93.62 \%$ & 0.953 & $94.25 \%$ & 0.958 \\
\hline Asyik & $95.19 \%$ & 0.938 & $94.83 \%$ & 0.594 \\
\hline DuaDM & $92.55 \%$ & 0.960 & $94.04 \%$ & 0.970 \\
\hline
\end{tabular}
pengujian model dengan algoritma Naïve Bayes, Support Vector Machine, Naïve Bayes berbasis Genetic Algorithm, dan Support Vector Machine berbasis Genetic Algorithm dengan menggunakan 4 (empat) jenis data calon gubernur jawa barat periode 2018-2023 (Pasangan calon gubernur pertama Ridwan Kamil-Uu Ruhzanul Ulum, kedua Tubagus Hasanuddin-Anton Charliyan, ketiga SudrajatAhmad Syaikhu dan keempat Deddy Mizwar-Dedi Mulyadi) dan masing-masing data dikelompokkan menjadi positif dan negatif dengan total data sebanyak 2643 data tweet. Model yang diuji akan menghasilkan nilai accuracy, precision, recall dan AUC dari setiap algoritma.

Hasil pengujian data tweet mengenai calon gubernur jawa barat periode 2018-2023 dengan Algoritma Support Vector Machine menghasilkan rata-rata akurasi 92,61\% dengan AUC 0,950, Algoritma Naïve Bayes menghasilkan rata-rata akurasi 93,29\% dengan AUC 0,525, Algoritma Support Vector Machine berbasis Genetic Algorithm menghasilkan rata-rata akurasi 93,03\% dengan AUC 0,869 dan Algoritma Naive Bayes berbasis Genetic Algorithm menghasilkan rata-rata akurasi $92,85 \%$ dengan AUC 0,543.

Dengan demikian model algoritma Support Vector Machine berbasis Genetic Algorithm adalah model algoritma terbaik dalam penelitian ini dan dapat memberikan hasil terbaik dalam pengujian dan pengklasifikasian analisis sentiment tweet calon 
gubernur jawa barat periode 2018-2023 dibandingkan dengan model algoritma Naïve Bayes berbasis Genetic Algorithm (NB-GA).

\section{REFERENSI}

Aggarwal, C. C. (2015). Data Mining. https://doi.org/10.1007/978-3-319-14142-8

Alfiah, F., Susanti, E., Kristinna, J., Ardiansyah, O. R., \& Pradipta, D. (2015). Manfaat Menganalisis Pengaruh Sosial Media. 6-8.

Balahur, A., Mihalcea, R., \& Montoyo, A. (2014). Computational approaches to subjectivity and sentiment analysis: Present and envisaged methods and applications. Computer Speech and Language, 28(1), 1-6. https://doi.org/10.1016/j.cs1.2013.09.003

Basari, A. S. H., Hussin, B., Ananta, I. G. P., \& Zeniarja, J. (2013). Opinion mining of movie review using hybrid method of support vector machine and particle swarm optimization. Procedia Engineering, 53, 453-462. https://doi.org/10.1016/j.proeng.2013.02.059

Bohang, F. K. (2017). Twitter 280 Karakter Resmi di Seluruh Dunia. Retrieved from tekno.kompas.com website: https://tekno.kompas.com/komentar/2017/11/0 8/08340057/twitter-280-karakter-resmi-diseluruh-dunia

Crc, H., Hofmann, M., \& Chisholm, A. (2016). Text Mining and Visualization Case Studies Using Open Source Tools.

Han, J., Kamber, M., \& Pei, J. (2012). Data Mining: Concepts and Techniques. In San Francisco, CA, itd: Morgan Kaufmann. https://doi.org/10.1016/B978-0-12-3814791.00001-0
Indrayuni, E. (2016). Analisa Sentimen Review Hotel Menggunakan Algoritma Support Vector Machine Berbasis Particle Swarm Optimization. Jurnal Evolusi Volume 4 Nomor 2 - 2016, 4(2), 20-27.

Jo, T. (2018). Text Mining. In Springer, Cham. https://doi.org/10.1016/B978-0-12-3969637.00010-6

Ramesh, B., \& Sathiaseelan, J. G. R. (2015). An Advanced Multi Class Instance Selection based Support Vector Machine for Text Classification. Procedia Computer Science, 57, 1124-1130. https://doi.org/10.1016/j.procs.2015.07.400

Sarlan, A., Nadam, C., \& Basri, S. (2015). Twitter Sentiment Analysis. ArXiv:1507.00955 [Cs, Stat], 212-216. https://doi.org/10.1109/ICIMU.2014.7066632

Wahyudi, M., \& Putri, D. W. I. A. (2016). ALGORITHM APPLICATION SUPPORT VECTOR MACHINE WITH GENETIC ALGORITHM OPTIMIZATION TECHNIQUE FOR SELECTION FEATURES FOR THE ANALYSIS OF. 84(3).

Witten, I. H., Frank, E., Hall, M. A., \& Pal, C. J. (2016). Data Mining: Practical Machine Learning Tools and Techniques. Data Mining: Practical Machine Learning Tools and Techniques, 1-621.

Zukhri, Z. (2014). Algoritma Genetika: Metode Komputasi Evolusioner untuk Menyelesaikan Masalah Optimasi. Yogyakarta: Andi. 